\title{
CONTRIBUTOS PARA UM DIREITO ADMINISTRATIVO LATINO-AMERICANO: O PAPEL DE AUGUSTÍN GORDILLO NAS CRÍTICAS DAS CATEGORIAS FUNDAMENTAIS
}

\author{
Emerson Affonso da Costa Moura \\ Eduardo Manuel Val ${ }^{2}$
}

\section{Resumo}

Os contributos do jurista Augustín Gordillo no Direito Administrativo latino-americano a partir de suas análises críticas de dados institutos fundamentais de origem romano-germânica é o tema posto em debate, a partir da análise do papel que exerce o jurista argentino assume na disciplina através da circulação de sua produção teórica, das principais críticas formuladas para algumas categorias essenciais na matéria e a tendência que tem o Direito Administrativo de realinhamento de seus elementos básicos. Busca o trabalho demonstrar a possibilidade de inserção do autor em um movimento crescente de crítica das matrizes europeias e busca da consolidação de uma independência epistemológica. Adota-se por método de abordagem da pesquisa o estruturalismo de forma a identificar na desconstrução de algumas de suas obras, a sua estrutura invariante e crítica.

Palavras-Chave: Direito Administrativo; Regime Administrativo; Poderes Administrativos; Prerrogativas; Augustín Gordillo.

\section{INTRODUÇÃO}

Orienta-se a atividade administrativa desenvolvida pelo Estado por um conjunto de institutos e princípios fundamentais que regem a Administração Pública e são sistematizados de forma sob normas jurídicas formando a disciplina jurídica de Direito Administrativo.

$\mathrm{Na}$ perspectiva comparada, esse regime jurídico da ação administrativa embora marcado pela presença de caracteres comuns e categorias próprias não é dotado de um objeto universal, mas forma uma disciplina especial e exorbitante no sistema anglo-saxão e um direito ordinário e comum no sistema da common law.

Neste tocante, as ordens jurídicas latino-americana no que tange ao Direito Administrativo se organizaram sob a influência não do modelo americano do sistema da common law, mas utilizando por paradigmas o sistema anglo-saxão, em especial, as contribuições do Direito Francês.

\footnotetext{
${ }^{1}$ Professor Assistente da Universidade Federal de Juiz de Fora, MG, Brasil. Doutorando em Direito pela Universidade do Estado do Rio de Janeiro (UERJ). Membro de Corpo Editorial da RDM e RDDA. E-mail: emersonacmoura@yahoo.com.br

${ }^{2}$ Professor Adjunto da Graduação e do Mestrado da UFF. Doutor em Direito pela PUC-RJ.E-mail: eduardoval11@hotmail.com
} 
Note, porém, que filiado ao sistema europeu-continental, o Direito Administrativo desses países, aderiu a uma disciplina exorbitante e derrogatória do direito comum, com prerrogativas e sujeições, potestades e restrições, que colocam a Administração Pública em uma posição superior e autoritária em relação ao cidadão.

Sob tal diapasão, a doutrina contemporânea da América Latina tem feito aportes críticos a adoção de categorias, em especial, do Direito Francês do século XVIII, que agravam um modelo de Estado autoritário, construídos sob a égide de um colonialismo de exportação, marcado pela ineficiência, corrupção e autoritarismo.

No Brasil, forma-se uma escola administrativa contemporânea, com destaque para os trabalhos da Universidade do Estado do Rio de Janeiro, que abordam de forma crítica científica, categorias centrais como a concepção do interesse público, as prerrogativas do ato administrativo, os poderes administrativos, dentre outros.

$\mathrm{Na}$ América Latina, vários autores trazem contributos a uma visão crítica dos institutos administrativos importados e para uma descolonização de saberes e a independência epistemológica da disciplina administrativa, de uma matriz eurocêntrica, que não se adéqua histórica, política e social com a realidade latino-americana.

Sob tal viés, exerce papel importante os aportes de Augustín Gordillo, cujas análises críticas de dados institutos fundamentais de origem romano-germânica, devido a circulação de sua produção teórica na região, tem auxiliado na tendência de realinhamento dos elementos básicos do Direito Administrativo.

Busca o presente trabalho, portanto, analisar o papel que tem exercido dada concepção crítica do jurista Augustín Gordillo sobre a relação entre Administração Pública e Administrado na sua obra de maior circulação Tratado de Direito Administrativo - no auxílio da desconstrução das concepções tradicionais de certos institutos administrativos.

Neste viés, pretende demonstrar a possibilidade de inserção da obra do autor em um primeiro e crescente estágio, de crítica das matrizes europeias que permeiam o Direito Administrativo e busca da consolidação de uma independência epistemológica da disciplina jurídica.

Para tanto, inicialmente aborda-se o status quo com a análise das categorias fundamentais importadas do modelo francês, de forma a fixar os elementos gerais incontroversos na doutrina tradicional, mas objeto de crítica pela escola contemporânea, em específico, do autor em comento.

Após, verifica-se o papel da contribuição de Augustin Gordillo no Direito Administrativo LatinoAmericano, com análise dentro da sua produção e circulação teórica, dos aportes trazidos à relação jurídica formada entre a Administração e o Administrado, de forma a definir a sua posição na construção de uma disciplina crítica.

Por fim, analisa-se a confluência de seu pensamento à escola contemporânea que sustenta uma relação administrativa humanizada, com realinhamento de suas categorias básicas como interesse público, discricionariedade e prerrogativa ao modelo marcado pela centralidade dos direitos fundamentais do cidadão. 
Adota-se por método de abordagem da pesquisa o estruturalismo de forma a identificar na desconstrução de algumas de suas obras, a sua estrutura invariante e crítica. Utilizam-se precipuamente aportes teóricos do autor, mas também, de outras doutrinas que contribuem no movimento.

\section{AS CATEGORIAS FUNDAMENTAIS E A RELAÇÃO ADMINISTRATIVA}

O Direito Administrativo encontrou sua construção, enquanto disciplina científica, na nas decisões da jurisdição administrativa francesa, que dissociada da atuação jurisdicional importou na sujeição da Administração à vontade da lei, porém, na sua imunização ao controle pelos demais poderes públicos ou a sociedade³.

Como as decisões do Conselho de Estado Francês não representavam a mera interpretação da lei com fins de sua aplicação, mas a criação de princípios para a solução dos casos concretos, gerou-se um "ativismo normativo", onde o juiz administrativo se substituía o Legislador como definidor normativo da Administração. ${ }^{4}$

A Administração Pública, portanto, no Estado Liberal não surge pela milagrosa submissão do Estado à lei e aos direitos fundamentais, mas de um modelo administrativo francês, onde a burocracia edita suas leis e tem sua jurisdição própria para julgá-la, como própria antítese da consagração da separação dos poderes 5 .

Essas construções legislativas de um órgão administrativo que conferiam privilégios da Administração Pública, denotam uma "nítida posição dominante da autoridade administrativa" e demonstram que o objetivo central era "cercear os administrados nos seus litígios com a Administração Pública das garantias". ${ }^{6}$

Por estas razões, a revolução liberal gera dois regimes jurídicos distintos exteriorizados em uma disciplina própria para a Administração Pública onde são conferidas prerrogativas sem equivalente nas relações privadas, e para os indivíduos, cuja sua esfera de liberdade de ação é restrita por sujeições?

Estruturou-se, em premissas teóricas que refletiam uma tensão dialética aparente entre a lógica da autoridade - voltada a consagração das instituições estatais e das prerrogativas públicas - e a lógica da liberdadeantevista na preservação do cidadão e de seus direitos fundamentais.

Isto porque, na prática formou-se um instrumental normativo e teórico de manutenção do status quo, que no caso do modelo latino-americano sua assimilação importava na consolidação dos caracteres do modelo de colonialização patrimonialista marcado pelo predomínio da corrupção, do nepotismo e da ineficiência na gestão

\footnotetext{
${ }^{3}$ BINENBOJM, Gustavo. Uma Teoria do Direito Administrativo: Direitos Fundamentais, Democracia e Constitucionalização. Rio de Janeiro: Renovar, 2006. p. 5

${ }^{4}$ OTERO, Paulo. Legalidade e Administração Pública: O sentido da vinculação administrativa à juridicidade. Coimbra: Almedina, 2003. p. 269.

${ }^{5}$ BINENBOJM, Gustavo. Op. cit.p. 6

${ }^{6}$ OTERO, Paulo. Op. cit. 276-277.

${ }^{7}$ FALLA, Fernando Garrido. Las Transformaciones Del Regime Administrativo. Madri: Instituto de Estudios Politicos, 1962.p. 4445.
} 
estatal ${ }^{8}$.

Consagrou-se o modelo de aparelho político-administrativo colonizador na América Latina onde o Estado atua como "órgão de opressão", com seus "privilégios e exércitos de servidores" submetendo ao particular para garantir a realização de seus fins - na época o fisco e defesa - porém, sem preocupação com cidadão e aperfeiçoamento dos serviços públicos. ${ }^{9}$

Tanto que o Direito Administrativo moderno erigiu como seus pilares, não a sujeição aos direitos fundamentais, mas o polissêmico conceito de interesse público e a ampla margem da discricionariedade administrativa com a proposição de um mérito insindicável, alheios aos princípios e regras constitucionais e ao controle material pelo Poder Judiciário.

Por um lado, adota-se como paradigma central, o conceito fluído e vago de interesse público ${ }^{10}$, com amplo grau de aceitabilidade e, portanto, legitimidade perante os cidadãos, porém, com margem de indeterminabilidade suficiente para que a Administração Pública defina dentre variada gama de conteúdo aquele que irá perseguir.

No Brasil, agrava-se a situação, com a sua concepção generalizada de supremacia proclamando-se a superioridade do interesse do grupo social com prevalência sobre qualquer interesse particular, além de conferir um complexo de privilégios a Administração Pública para a sua persecução, mas que coloca-a em posição perigosamente exacerbada ${ }^{11}$.

Em outro ângulo, com discricionariedade administrativa compreende-se o espaço de liberdade decisória concedida à Administração Pública na eleição entre os indiferentes jurídicos, inserto na esfera de atribuição concedida pela norma jurídica e de acordo com a formulação dos juízos de conveniência e oportunidade promovidos $^{12}$.

Nesta ordem, compreende o mérito administrativo os juízos formulados pela Administração Pública acerca da conveniência, oportunidade, equidade e demais critérios utilizados na decisão administrativa que são definitivos e inquestionáveis perante o poder Judiciário ${ }^{13}$.

Embora se adéqüe a necessária dinâmica da atividade administrativa, em um contexto de multiplicidade e complexidade das demandas sociais que escapa à previsibilidade do legislador, a existência de um campo de

\footnotetext{
${ }^{8}$ Sobre o tema, vide: FAORO, Raymundo. Os Donos do Poder. 15 ed. São Paulo: Editora Globo, 2000. FREYRE, Gilberto. Casagrande e Senzala. 39 ed. Rio de Janeiro: Record, 2000 e NUNES, Edson. A gramática política do Brasil - clientelismo e insulamento burocrático. Rio de Janeiro: Jorge Zahar Editor, 1997.

${ }^{9}$ BOMFIM, Manoel. A América Latina: Males de Origem. Rio de Janeiro: Centro Edelstein de Pesquisas Sociais, 2008. p. $100-101$.

${ }^{10}$ BINENBOJM, Gustavo. Op. cit.p. 3.

${ }^{11} \mathrm{O}$ tema foi amplamente tratado em: MOURA, Emerson Affonso da Costa. Um Fundamento do Regime Administrativo: $O$ Princípio da Prossecução do Interesse Público. Rio de Janeiro: Lumen Juris, 2014.

${ }^{12}$ DI PIETRO, Maria Sylvia Zanella. Da Discricionariedade Administrativa. São Paulo: Atlas, 1990. p. 92.

${ }^{13}$ DI PIETRO, Maria Sylvia Zanella. Da Discricionariedade Administrativa. São Paulo: Atlas, 1990. p. 92.
} 
escolha na atuação administrativo não representa intangibilidade do seu mérito aos limites impostos pela ordem jurídica ${ }^{14}$.

Todavia, a discricionariedade administrativa tem sido utilizada como um amplo espaço de escolha ignorado que existem fins constitucionais a serem observados pela atuação estatal, com a definição de prioridades e dispêndio dos recursos estatais, que vinculam os poderes públicos construindo no espaço de sua atuação limites objetivos invioláveis ${ }^{15}$.

Forma-se, portanto, o arcabouço teórico de uma Administração Pública Subordinativa de irradiação hierarquizada e linear que começa a apresentar esgotamento de suas formas de atuação coercitiva com a inviabilidade de atendimento das múltiplas demandas sociais oriunda da crescente complexidade da sociedade ${ }^{16}$.

A crescente reaproximação teórica do Direito Administrativo com os demais ramos do Direito Público, ocorre a partir do fenômeno da Constitucionalização do Direito, onde a erradicação das normas constitucionais ao regime jurídico-administrativo abrange, também, a reorientação da persecução estatal à promoção dos direitos e garantias fundamentais.

Volta-se a doutrina, a desconstrução dos pilares de uma relação jurídico-administrativa tipicamente formal e subordinativa, de natureza notadamente unilateral, subordinativo e esporádico, para a elevação do administrado à condição de cidadão, como centro de convergência dos institutos estatais em torno da pessoa humana.

O tema será tratado a seguir.

\section{OS APORTES TEÓRICOS DE AUGUSTIN GORDILLO NA RELAÇÃO ADMINISTRATIVA}

Um dos principais teóricos administrativos da américa Latina, cuja obras alcançaram ampla circulação na América Latina, o autor Augustin Gordillo tem importante contribuição com a sua visão crítica da concepção de inúmeros institutos da disciplina, dentre os quais da relação jurídico-administrativa hierarquizada.

Sua expressiva circulação, decorrente precipuamente de sua ampla rede de atuação acadêmica, que abrange desde instituições nacionais como a Universidade de Buenos Aires onde atua no Programa de Pós-

\footnotetext{
${ }^{14}$ MELLO, Celso Antonio Bandeira de. Discricionariedade e Controle Jurisdicional. São Paulo: Malheiros, 1992. p. 44-48.

${ }^{15}$ Há casos em que a Constituição consagra de forma explícita os fins esperados, como ocorre com a obrigatoriedade da prestação universal da educação fundamental e medicina de urgência, de modo que condicionar sua promoção à discricionariedade administrativa e conformação legislativa seria violação dos direitos individuais e políticos, cujo exercício pressupõe a garantia mínima do bem-estar, que envolve a realização de condições econômicas e sociais básicas. MOURA, Emerson Affonso da Costa. Do Controle Jurídico ao Controle Social das Políticas Públicas: Parâmetros a Efetividade dos Direitos Sociais. Mimeografado. 2010.p. 10

${ }^{16}$ MOREIRA NETO, Diogo de Figueiredo. Mutações do Direito Administrativo. 2 ed. atual e ampla Rio de Janeiro: Renovar, 2001. p. 26-27.
} 
Graduação stricto sensu e internacionais como no Centro de Direito Público Europeu em Atenas onde é Conselheiro da Administração.

No campo profissional, participa do Tribunal Administrativo do Fundo Monetário Internacional e da Organização dos Estados Americanos em Washington D.C., da Organização Internacional do Trabalho em Genebra e da Organização das Nações Unidas de Nova York.

Dentre outras atividades, há a direção de Conselhos Editoriais e participação de revistas jurídicas na América Latina e Europa, fundação e presidência da Fundação de Direito Administrativo na Argentina e do Instituto Internacional de Direito Administrativo Latino, bem como, cargos políticos na Administração Nacional.

Inegável a ampla publicação, com centenas de artigos divulgados em periódicos nacionais e estrangeiros, bem como, em obras coletivas, além de vinte e obras publicadas nos idiomas espanhol, português e italiano, dentre os quais destacam-se para este estudo o clássico Tratado de Direito Administrativo ${ }^{17}$ em 4 volumes e a Administração Paralela ${ }^{18}$.

Nestas obras, o autor rompe com dois paradigmas generalizadamente difundidos: o primeiro que a disciplina administrativa é fruto das revoluções liberais, mas que enquanto se relaciona com o exercício da função estatal de persecução do interesse público pode-se dizer é realizado desde o nascimento da figura do próprio Estado ${ }^{19}$.

Insere-se, portanto, no movimento de superação da quase mítica concepção de surgimento do Direito Administrativo com as revoluções liberais, em específico, que as normas advindas da disciplina, foram responsáveis por garantir os direitos fundamentais dos cidadãos.

Em análise feita pelo autor, às leis de procedimento administrativo dos referidos países, inclusive, o Brasil, verifica que tais normas assumem o papel de limitação para o particular e atribuição de prerrogativas para a Administração Pública, sendo que critérios em defesa do administrado que na realidade são poucos reconhecidos. ${ }^{20}$

Assim, utiliza critérios apriorísticos em favor do agente público e seu ato é contra o particular a quem afeta, "a favor do poder, em contra do indivíduo. Em mão contrária da história atual", se confundindo a Administração Pública como "fiel tutora do interesse público e o particular seu inimigo contraparte". ${ }^{21}$

Fixa, portanto, que a identidade da Administração com a sociedade - e contrária ao indivíduo - e, portanto, do interesse que move a Administração com o público é apenas "uma variante sofisticada, mas não substancialmente distinta daquelas frases que vieram no Direito Administrativo Absolutista”, como os princípios

\footnotetext{
${ }^{17}$ GORDILLO, Augustin. Tratado de Derecho Administrativo. Tomo 1, 2, 3 e 4. 6 ed. Belo Horizonte: Del Rey, 2003.

${ }^{18}$ GORDILLO, Augustin A. La Administración Paralela. Madrid: Editorial Civitas, S.A., 1988.

${ }^{19}$ GORDILLO, Agustín. Tratado... Op. cit.p. 40

${ }^{20}$ GORDILLO, Augustin A. La Administración... p. 50.
} 
do the King can do no wrong. ${ }^{22}$

O uso de tal sofisma apresentado como sendo paradigma provém do Estado de Polícia Medieval e sustenta sem argumentação que prevalecem os atos "do funcionário disfarçado de Administração e não do indivíduo", de modo que as "arbitrariedades administrativas não controladas judicialmente em tempo oportuno, são o caldo de cultivo da corrupção." ${ }^{23}$

Ademais, baseia-se em uma "afirmação categórica que não se pode demonstrar" que o poder representa "sempre e necessariamente" no caso concreto, "o interesse público, o bem comum, a boa ordem da comunidade ou qualquer frase que queira eleger", funcionando como o "mais ilógico argumento de autoridade", com "uma essência sobrenatural". ${ }^{24}$

Por efeito, adota-se uma posição de partida favorável a Administração "transmutada em Olímpio" que atua de forma imparcial e independente, em lugar de in favorem liberatis in dubio por administratione, sob o manto que serve ao interesse público, "como se ao bem comum não interessasse a tutela da liberdade individual". 25

Assim, a concessão de prerrogativas aos agentes estatais como a presunção de legitimidade, o não reconhecimento de efeitos suspensivos aos recursos contra atos administrativos, a auto executoriedade concede uma "resposta coerentemente autoritária" ao modelo marcado pelo descumprimento das garantias do cidadão e da legalidade. ${ }^{26}$

Assim, a prerrogativa de legitimidade dos atos administrativos representa um pensamento "político estatista e autoritário", mesmo quando veiculado através de norma legal e com fundamento no interesse público, pois é irrazoável e inconstitucional, permitir que atos manifestamente ilegítimos presumam-se legítimos e produzam efeitos até sua comprovação. ${ }^{27}$

Já a prerrogativa de execução forçada não prevista na ordem jurídico-positiva, em uma realidade marcada pelo "demasiado autoritarismo e excesso de poder", não coaduna com um Estado de Direito exceto se previstas através de leis expressas e concretas para situações determinadas, sob pena de "cair em um verdadeiro Estado de Polícia”. ${ }^{28}$

Em apontamento certeiro, lembra que todas as prerrogativas concedidas na relação administrativa devem ter fundamento positivo, como "um reflexo de todo sistema jurídico aplicávele não podem ser resolvidos a

\footnotetext{
${ }^{21}$ GORDILLO, Augustin. Tratado de... Tomo 1 p. 4-5.

${ }^{22}$ GORDILLO, Augustin. Tratado... Tomo 1. Op. cit.p. 5.

${ }^{23}$ GORDILLO, Augustin. Tratado... Tomo 1. Op. cit.p. 5.

${ }^{24}$ GORDILLO, Augustin. Tratado... Tomo 1. Op. cit.p. 5.

${ }^{25}$ GORDILLO, Augustin. Tratado... Tomo 1. Op. cit.p. 6.

${ }^{26}$ GORDILLO, Augustin. Tratado... Tomo 1. Op. cit.p. 9

${ }^{27}$ GORDILLO, Augustin. Tratado... Tomo 3. Op. cit. V-4 e V-5.

${ }^{28}$ GORDILLO, Augustin. Tratado... Tomo 3. Op. cit. V-33.
} 
nível puramente doutrinário" sem "fundamentos sistemáticos e não pontuais da ordem jurídica". ${ }^{29}$

O próprio interesse público não pode ser tido como antagônico com os interesses privados, sob título de corresponder a uma "insalvável antítese lógica", pois "ao destruir os direitos dos indivíduos em prol da coletividade, há que se destruir também, ao mesmo tempo, a base necessária de ordem e justiça sobre a qual essa coletividade inteira repousa". ${ }^{30}$

Note, portanto, que na vanguarda de uma independência epistemológica das matrizes teóricas francesas, o autor aponta que a relação jurídico-administrativa em seus caracteres fundamentais - o interesse público e as prerrogativas - precisam se adequar ao arcabouço do Estado de Direito.

Insere-se em um movimento de crítica as categorias fundamentais e tentativa de realinhamento da teoria administrativa à concepção de centralidade do homem e de seus direitos no ordenamento jurídico, com a transposição de uma Administração Pública Autoritária para um modelo coordenado com a sociedade.

O tema será tratado a seguir.

\section{A NOVA CONFIGURAÇÃO DA RELAÇÃO ADMINISTRATIVA}

Com ascensão axiológica dos direitos fundamentais, apreende-se uma nova ordem de relação entre Administração e Cidadão, com cunho eminentemente multilateral e coordenativo, baseado na centralidade do indivíduo e na ampliação dos espaços que propiciem sua participação na gestão pública e a durabilidade das relações administrativas ${ }^{31}$.

No que tange ao interesse público, embora a Administração Pública oriente-se sob o influxo desses, disso não decorre uma ilimitada esfera de liberdade na sua definição ou sua precedência abstrata sobre os interesses privados, cuja pressuposta validade e posição hierárquica, tornaria dispensável o exame prévio de sua referência na ordem jurídica ${ }^{32}$.

Falta a supremacia do interesse público sobre o privado os fundamentos jurídico-positivos de validade necessários a um princípio fundamental iminente, em razão de sua descrição abstrata e referida prevalência absoluta, bem como, de sua incompatibilidade com outros postulados normativos, em especial, da

\footnotetext{
${ }^{29}$ GORDILLO, Augustin. Tratado... Tomo 3. Op. cit. V-1 e V-2.

${ }^{30}$ GORDILLO, Agustín. Tratado... Tomo II. Op. cit. VI-31.

${ }^{31}$ BAPTISTA, Patrícia. Ob. cit.p. 128-130.

${ }^{32}$ Corresponderia a um dos cânones do direito público, em razão do seu reconhecimento no ordenamento jurídico e de sua aceitação pacífica na doutrina, que o tornaria insuscetível de qualquer limitação ou temperamento por outros princípios que compõem a ordem jurídica. MELLO, Celso Antônio Bandeira de. Curso de Direito Administrativo. 21. ed. rev. e atual. São Paulo: Malheiro, 2006. p. 69-70.
} 
proporcionalidade e concordância prática ${ }^{33}$.

Sob a ótica constitucional deve ser considerada não uma hierarquia preexistente de supremacia do interesse coletivo, porém, uma axiológica e elementar com o reconhecimento da precedência natural dos direitos e garantias fundamentais, permitida sua excepcional restrição pelo interesse público desde que justificada a sua limitação.

Inverte-se, desta maneira, na tensão promovida entre interesses públicos e privados a imposição do ônus argumentativos para os interesses do grupo social que devem ser capaz de sobrepujar os direitos individuais, no exame do caso concreto com o emprego do princípio da proporcionalidade, em observância a centralidade assumida pelos direitos fundamentais ${ }^{34}$.

Com este deslocamento do fundamento da dogmática administrativa da supremacia do interesse público, as restrições e privilégios concedidos na realização das finalidades estatais, alçam um novo fundamento de validade sob a ótica ampliativa de uma Administração Pública garantidora.

Enquanto espécies de potestad pública concedidas aos agentes estatais em razão das tarefas de que incumbem realizar, as prerrogativas administrativas não se aplicam em abstrato e com prevalência absoluta, porém, na medida de sua necessidade à persecução do interesse público e desde que em equilíbrio com os direitos dos administrados.

Sujeita sua incidência, deste modo, a ponderação com os demais bens e valores conflitantes, tendo por foco a precedência natural dos direitos fundamentais na ordem jurídica e o sólido sistema de garantias projetado pela Constituição, que buscam compensar a sujeição do administrativo às prerrogativas concedidas a Administração Pública ${ }^{35}$.

Transmuta-se, portanto, a concepção da discricionariedade administrativa de uma ampla esfera de escolha na persecução do interesse público não sujeito a controle pelos poderes públicos a um campo de ponderações proporcionais e razoáveis entre os bens e interesses constitucionais, sujeita a controle exercido pelo Poder Judiciário ${ }^{36}$.

Isto importa no estreitamento do mérito administrativo pelos procedimentos técnicos e jurídicos definidos pela Constituição ou lei que permitam o exercício da opção política capaz de garantir a otimização do

\footnotetext{
33 ÁVILA, Humberto. Repensando o "Princípio da Supremacia do Interesse Público Sobre o Particular" SARMENTO, Daniel (Org). Interesses Públicos vs. Interesses Privados: Desconstruindo o Princípio de Supremacia do Interesse Público. Rio de Janeiro: Lumen Juris, 2005. p. 186-190.

${ }^{34} \mathrm{~A}$ imposição de ônus argumento ao direito individual na sua tensão com os interesses do grupo social se demonstra incompatível com um Estado Constitucional de Direito marcado pela centralidade do homem e reconhecida a fundamentalidade de seus direitos. Assim, no conflito devem existir maiores razões para a solução exigida pelos bens coletivos do que para aquelas exigidas pelos direitos individuais. AVILA, Humberto. Ob. cit.p. 187.

${ }^{35}$ CASSAGNE, Juan Carlos. Derecho Administrativo. Tomo 3. 8. ed. Buenos Aires: Abeledo-Perrot, 2006. p. 25.

${ }^{36}$ CUNHA, Rubem Dário Peregrino. A juridicização da discricionariedade administrativa. Salvador: Vercia, 2005. p. 168-172.
} 
grau de legitimidade da decisão administrativa com a integração nos limites de sua competência ao atendimento do interesse público ${ }^{37}$.

Envolve, também, a submissão do espaço decisório ao feixe de princípios constitucionais, que passam a orientar os juízos de valoração do administrador pelos critérios de razoabilidade, isonomia e demais, assegurando a congruência da decisão administrativa ao interesse legal e o impedimento de sua tradução em arbitrariedade ${ }^{38}$.

Ademais, o reconhecimento da submissão imediata da ação administrativa a observância dos preceitos constitucionais conduz à superação da clássica dicotomia entre atos vinculados e discricionários com o redimensionamento da adstrição de todos os atos administrativos a certo grau de juridicidade, definido pelo estabelecimento de critérios em vista ao equilíbrio entre os poderes ${ }^{39}$.

Propõe-se uma menor vinculação a juridicidade com rasa ingerência judicial nos atos onde haja predomínio da especialização técnico-funcional da burocracia ou acentuado lastro político da matéria, e maior adstrição e um controle denso pelo Poder Judiciário naqueles capazes de impor restrições aos direitos fundamentais ${ }^{40}$.

A erradicação das normas constitucionais ao regime jurídico-administrativo abrange, também, a reorientação da persecução estatal à promoção dos direitos fundamentais reordenando a relação entre a Administração e o Administrado ao eixo nodal na dignidade da pessoa humana e a centralidade dos direitos do homem ${ }^{41}$.

Sob um vértice, conduz ao realinhamento dos níveis de concentração do poder público na persecução dos interesses sociais mediante a subsidiariedade da atuação estatal e a intervenção precípua das organizações privadas nas atividades que não demandem em razão da complexidade ou necessidade uma ação estatal concentrada e imperativa ${ }^{42}$.

Abrange em outro ângulo, a expansão da participação dos cidadãos nos processo de formação da decisão administrativa, que envolve desde a aferição de suas legítimas expectativas acerca da atuação estatal até as deliberações coletivas promovidas no âmbito da Administração, racionalizando e legitimando a gestão pública ${ }^{43}$.

\footnotetext{
${ }^{37}$ MOREIRA NETO, Diogo de Figueiredo. Legitimidade e Discricionariedade. 3 ed. Rio de Janeiro: Forense, 1998. p. 7-8 e 32-33.

${ }^{38}$ BAPTISTA, Patrícia. Ob. cit.p. 91.

${ }^{39}$ KRELL, Andreas J. Discricionariedade Administrativa e Proteção Ambiental: o controle dos conceitos jurídicos indeterminados e a competência dos órgãos ambientais. Um Estudo Comparativo. Porto Alegre: Livraria do Advogado, 2004. p. 45.

${ }^{40}$ BINENBOJM, Gustavo. Op. cit. Capítulo V.

${ }^{41}$ JUSTEN FILHO, Marçal. O Direito Administrativo de Espetáculo. Fórum Administrativo Direito Público. Belo Horizonte, ano 9, n 100 jun. 2009.p. 150-152.

${ }^{42}$ MOREIRA NETO, Diogo de Figueiredo. Mutações.... p. 20-21.

${ }^{43}$ MARTINS JUNIOR, Wallace Paiva. Transparência Administrativa, Publicidade, Motivação e Participação Popular. São Paulo: Saraiva, 2004.p. 298, 304 e 331.
} 


\title{
CONCLUSÃO
}

Buscou o presente trabalho, analisar o papel exercido pela doutrina do autor Augustín Gordillo no que tange a relação formada entre Administração Pública e Administrado, no movimento crescente na América Latina de desconstrução das concepções tradicionais de certos institutos administrativos.

Como visto, centra-se a relação jurídico-administrativa sob alguns pilares fundamentais: a concepção de um interesse público capaz de nome da coletividade submeter qualquer interesse privado e a concessão da discricionariedade de variadas prerrogativas para a Administração Pública melhor perseguí-los.

De origem na matriz europeia, em especial, de dada Escola Francesa, tais categorias foram objetos de críticas do Augustin Gordillo que fixou a necessidade de sua readequação ao modelo de Estado de Direito com a necessidade de sua previsão normativa e de compatibilização com os direitos fundamentais.

Tal pensamento é possível adequar a linha que tem seguido parte da doutrina contemporânea na América Latina, de revisão das categorias fundamentais do Direito Administrativo de forma a adéqua-lo aos influxos do constitucionalismo contemporâneo marcado por um novo papel do homem.

Assim, busca-se uma concepção de um interesse público convergente e ponderável com outros bens e interesses legitimamente tutelados pela ordem jurídica e da discricionariedade administrativa como um espaço dentro de margens previamente definidas na Constituição e, assim, possivelmente controlados.

De fato, isto importa em um afastamento das concepções tradicionais das categorias e as construções de novas visões adequadas à realidade teórica e institucional da América Latina, o que aponta para formação de um Direito Administrativo com caracteres próprios, independente epistemologicamente de suas matrizes.

Tal movimento, no estágio primário ao qual se encontra, tende a refletir precipuamente um amadurecimento teórico e desenvolvimento doutrinário, capaz de dentro dos limites conformativos do próprio Direito, trazer novas perspectivas para a aplicação de uma disciplina administrativa, mais adequada às realidades sociais.

\section{CONTRIBUTIONS TO LATIN AMERICAN ADMINISTRATIVE LAW: AUGUSTIN GORDILLO'S ROLE IN THE CRITICS ON FUNDAMENTAL CATEGORIES}

\begin{abstract}
The contributions of the jurist Augustín Gordillo in Latin American Administrative Law from his critical analyzes of data fundamental institutes of Roman-Germanic origin is the subject put in debate, starting from the analysis of the role that the Argentine jurist takes in the discipline through the circulation of its theoretical production, of the main criticisms formulated for some essential categories in the matter and the tendency that has the Administrative Law of realignment of its basic elements. The paper seeks to demonstrate the possibility of
\end{abstract}


insertion of the author into a growing movement of critique of European matrices and the search for the consolidation of an epistemological independence. Structuralism is adopted by method of approach of the research in order to identify in the deconstruction of some of its works, its invariant and critical structure.

Keywords: Administrative Law; Administrative Regime; Administrative Powers; Prerogatives; Augustín Gordillo.

\section{REFERENCIAS}

BARCELLOS, Ana Paula de. Constitucionalização das Políticas Públicas em Matéria de Direitos Fundamentais: O Controle Político-Social e o Controle Jurídico no Espaço Democrático in Revista de Direito do Estado. Ano 1. n. 3.2006 .

BINENBOJM, Gustavo. Uma Teoria do Direito Administrativo: Direitos Fundamentais, Democracia e Constitucionalização. Rio de Janeiro: Renovar, 2006.

BOMFIM, Manoel. A América Latina: Males de Origem. Rio de Janeiro: Centro Edelstein de Pesquisas Sociais, 2008.

CASSAGNE, Juan Carlos. Derecho Administrativo. Tomo 3. 8. ed. Buenos Aires: Abeledo-Perrot, 2006.

CUNHA, Rubem Dário Peregrino. A juridicização da discricionariedade administrativa. Salvador: Vercia, 2005. p. 168-172.

DI PIETRO, Maria Sylvia Zanella. Da Discricionariedade Administrativa. São Paulo: Atlas, 1990.

FALLA, Fernando Garrido. Las Transformaciones Del Regime Administrativo. Madri: Instituto de Estudios Politicos, 1962.

FAORO, Raymundo. Os Donos do Poder. 15 ed. São Paulo: Editora Globo, 2000.

FREYRE, Gilberto. Casa-grande e Senzala. 39 ed. Rio de Janeiro: Record, 2000.

GORDILLO, Augustin. Tratado de Derecho Administrativo. Tomo 1, 2, 3 e 4.6 ed. Belo Horizonte: Del Rey, 2003.

GORDILLO, Augustin A. La Administración Paralela. Madrid: Editorial Civitas, S.A., 1988.

Curso de Direito Administrativo. 21. ed. rev. e atual. São Paulo: Malheiro, 2006.

JUSTEN FILHO, Marçal. O Direito Administrativo de Espetáculo. Fórum Administrativo Direito Público. Belo Horizonte, ano 9, n 100 jun. 2009.

KRELL, Andreas J. Discricionariedade Administrativa e Proteção Ambiental: o controle dos conceitos jurídicos indeterminados e a competência dos órgãos ambientais. Um Estudo Comparativo. Porto Alegre: Livraria do Advogado, 2004.

MARTINS JUNIOR, Wallace Paiva. Transparência Administrativa, Publicidade, Motivação e Participação 
Popular. São Paulo: Saraiva, 2004.

MELLO, Celso Antonio Bandeira de. Discricionariedade e Controle Jurisdicional. São Paulo: Malheiros, 1992.

MOREIRA NETO, Diogo de Figueiredo. Mutações do Direito Administrativo. 2 ed. atual e ampla Rio de Janeiro: Renovar, 2001.

Legitimidade e Discricionariedade. 3 ed. Rio de Janeiro: Forense, 1998. p. 7-8 e 32-33.

MOURA, Emerson Affonso da Costa. Um Fundamento do Regime Administrativo: O Princípio da Prossecução do Interesse Público. Rio de Janeiro: Lumen Juris, 2014.

Do Controle Jurídico ao Controle Social das Políticas Públicas: Parâmetros a Efetividade dos Direitos Sociais. Mimeografado. 2010

NUNES, Edson. A gramática política do Brasil - clientelismo e insulamento burocrático. Rio de Janeiro: Jorge Zahar Editor, 1997.

OTERO, Paulo. Legalidade e Administração Pública: O sentido da vinculação administrativa à juridicidade. Coimbra: Almedina, 2003.

SARMENTO, Daniel (Org). Interesses Públicos vs. Interesses Privados: Desconstruindo o Princípio de Supremacia do Interesse Público. Rio de Janeiro: Lumen Juris, 2005.

Trabalho enviado em 07 de julho de 2016.

Aceito em 19 de dezembro de 2016. 